Sno, H. N., Linszen, D. H. \& De Jonghe, F. (1992) Déjà vu experiences and reduplicative paramnesia. British Journal of Psychiatry (in press).

Academic Medical Centre

Herman N. SNo

Meibergdreef 9

1105 AZ Amsterdam

The Netherlands

\section{Iron Maiden's déjà vu}

SIR: Sno, Linszen and de Jonghe have reviewed a number of descriptions of déjà vu in poetry and literature (Journal, April 1992, 160, 511-518). There is another particulary striking example. It is the song entitled "Déjà-vu" by Dave Murray and Steve Harris (1986) from the album Somewhere in Time by the rock group Iron Maiden. It vividly illustrates many of the points made by Sno et al in their article. The song gives an accurate phenomenonological description of déjà vu. It implicitly suggests reincarnation as an explanation and it refers explicitly to precognition ("And you feel you know what's coming next") and to feelings of depersonalisation ("And you feel that this moment in time is surreal"). The full lyrics are reproduced here with the kind permission of Iron Maiden Publishing (Overseas) Ltd, administered by Zomba Music Publishers Ltd.

"When you see familiar faces

But you can't remember where they're from

Could you be wrong?

When you've been particular places

That you know you've never seen before

Can you be sure?

'Cause you know this has happened before

And you know that this moment in time is for real

And you know when you feel déjà-vu.

Chorus:

Feels like I've been here before (rpt. four times)

Ever had a conversation

That you realise you've had before

Isn't it strange?

Have you ever talked to someone

And you feel you know what's coming next

It feels pre-arranged.

'Cause you know that you've heard it before And you feel that this moment in time is surreal

'Cause you know when you feel déjà-vu.

Chorus

Sno et al suggest that psychiatrists "should be encouraged to overstep the limits of psychiatric literature and read literary prose and poetry as well" because "novelists and poets excel in [the] ability to depict subjective experiences". While agreeing with this point of view, I would go futher. Literature and art are capable of eliciting an emotional response in the person who experiences them. This can lead to a far deeper empathic or subjective understanding of an experience than is possible from a scientific description. Wide reading and exposure to the arts enables us to share, if only partially and incompletely, the experiences of our patients. We can understand them better, not just at an intellectual level, but as people like ourselves.

\section{Mental Health Advice Centre}

Bill Plummer

\section{Radnor Park Avenue}

Folkestone

Kent

\section{Hypnotised lobsters}

SIR: With great interest I read Henry Rollin's column: "A Hundred Years Ago" in the January 1992 volume of the Journal.

Most readers will no doubt consider the tale of The Hypnotised Lobster a droll little piece demonstrating the gullibility of our forebears. By sheer chance, however (or was it some form of Jungian synchronicity?), I had two days earlier chanced upon a description of the technique required to hypnotise a lobster. It comes from a book written by an acquaintance of mine and tells of his 12-year-old son entrancing the still-living ingredients of the family dinner while aboard their yacht. In the interests of extending the mesmeric repertoires of your readers, I quote the relevant passage.

"Lobster for dinner. While the water boiled, Mark hypnotized the lobsters, which makes the dinner party much more comfortable for the lobster. He held each lobster upside down, with the pincers and head on the cockpit seat. Then he slowly stroked them, moving his fingers upward along the back and over the curve of the tail. In a matter of minutes, he had all eight lobsters, standing on their heads, blissed out, motionless, entranced.

We popped them into the boiling water, and they were dead and cooking before they even awoke". (Cameron, 1991)

Should anyone doubt the veracity of this story I would add that the book contains a photograph showing the crustaceans neatly arrayed on their heads, awaiting their moment of destiny.

Cameron, D. (1991) Wind, Whales and Whisky. A Cape Breton Voyage. Toronto: MacMillan Canada.

Suite 511

Simon A. Brooks

Bedford House

1595 Bedford Highway

Bedford NS

B4A 3 Y4, Canada 